\title{
Evaluation of Continuous Application Technology for Delivery of the Biocontrol Agent Pseudomonas putida 06909-rif/nal
}

K. Steddom, Texas Agricultural Experiment Station, 2301 Experiment Station Road, Bushland 79012-0010; and
J. A. Menge, Department of Plant Pathology, University of California, Riverside 92521-0001

\begin{abstract}
Steddom, K., and Menge, J. A. 2001. Evaluation of continuous application technology for delivery of the biocontrol agent Pseudomonas putida 06909-rif/nal. Plant Dis. 85:387-392.

We evaluated a commercial field fermentor as a means of culturing and delivering a bacterial biocontrol agent, Pseudomonas putida 06909-rif/nal, through irrigation water. There was no evidence of contamination in 12-hour cultures produced by the fermentor. It produced 120 liters of inoculum at $5 \times 10^{8} \mathrm{CFU} / \mathrm{ml}$ after 12-hour fermentations, allowing two applications per day. Dilutions up to $1: 100,000$ of inoculum of $P$. putida 06909 -rif/nal produced by the fermentor allowed the biocontrol agent to effectively colonize soil in greenhouse trials. Bacteria produced in 19-hour fermentations colonized soil better than bacteria produced in 12-hour fermentations. Ten repetitive applications of $P$. putida 06909 -rif/nal yielded soil population levels similar to those from a single application at 10 -fold greater concentrations. Repetitive applications of lower concentrations may be a cost-effective method for delivering bacterial biocontrol agents to large acreages. This work suggests that the commercial field fermentor would be a viable instrument for delivering bacterial biocontrol agents for commercial-scale field applications.
\end{abstract}

Biological control has been proposed as a replacement for chemical control of plant diseases or for control of diseases that are not economically controlled with chemicals $(2,3,5,7,10,11,15)$. Unfortunately, few commercial biocontrol products have had commercial success $(2,4,5)$. Powell (12) indicated "the real problem for biological control is to deliver an active agent to the site where it is required and keep it there while activity is required." Schroth and Weinhold (15) called rhizosphere investigations "a masochist's delight." There are many reasons why organisms fail to establish or control disease, including failure to colonize the target site, failure to survive for a sufficient length at the target site, and lack of activity at the target site. Schroth and Becker (14) reviewed examples of seed-inoculated organisms that do not colonize distal roots effectively and, therefore, do not protect against disease. Kim et al. (6) and Schippers et al. (13) reported declines in populations of biocontrol agents throughout the growing season. Troxler et al. (18) found a large percentage of their inoculum added to the soil was present as viable but non-culturable cells 8 months after inoculation. These cells were probably not active as biocontrol agents. Even when these difficulties are overcome, many organisms require a high population

Corresponding author: Karl Steddom E-mail: K-Steddom@tamu.edu

\section{Accepted for publication 13 November 2000.}

Publication no. D-2001-0122-02R

(C) 2001 The American Phytopathological Society to achieve biocontrol, and application costs may be prohibitive (10).

Many researchers have suggested insufficiencies in biological control may be overcome through inundative means (3), but few have tried this due to the high cost of applications. Bahme et al. (1) showed that repetitive applications of Pseudomonas fluorescens through a drip-irrigation system improved colonization of potato root systems over seed-piece inoculation or incorporation of bacteria-impregnated granules into the soil. Repeated inoculations increased the nodulation effectiveness of a strain of Rhizobium luguminosarum (9). Repetitive applications in irrigation water, therefore, are an effective means of delivering a biocontrol agent to the root system. Roots will grow where water is available and the bacteria that colonize roots are those present in bulk soil $(1,14)$.

Eco Soil Systems (San Diego, CA) developed a self-contained field fermentor, called the BioJect, to overcome the costs of repetitive applications of bioinoculants (Fig. 1). The BioJect is capable of producing 120 liters of bacterial inoculum under field conditions. It has facilities to sanitize water through sand and micron filtration followed by UV irradiation, heat, and chill fermentation to maintain optimum temperatures, sanitize all equipment between successive fermentations with peracetic acid, and inject bacterial fermentation into an existing irrigation system, all through an automated computer controller. It can handle up to three concentrated media sources and three refrigerated inoculum sources, allowing flexible management strategies. It is being used on many golf courses as part of a commercial biocontrol system. We are currently evaluating the potential of this system for control of Phytophthora root rot of citrus in commercial citrus orchards.

Pseudomonas putida strain 06909 was originally isolated as a contaminant on a field isolate of Phytophthora citrophthora. It effectively reduces populations of $P$. citrophthora and $P$. parasitica, the causal agents of Phytophthora root rot of citrus, in greenhouse studies and $P$. citrophthora in seedbed trials $(19,20)$. It actively adheres to the hyphae of Phytophthora, restricts growth of the pathogen in vitro, and produces an iron chelating siderophore, pyoverdine, but shows no evidence of antibiosis $(21,23)$. In field trials, applications of $P$. putida 06909 -rif/nal with every irrigation increased populations of the bacteria, as well as its biocontrol efficacy against $P$. parasitica over that of single yearly applications at the start of the irrigation season $(16,17)$. It is unclear whether these increases were due to the larger number of bacteria applied to the continuous application treatment or if continuous applications allowed for better colonization or survival of the bacteria.

The purpose of this study was to determine first, if a commercial field fermentor

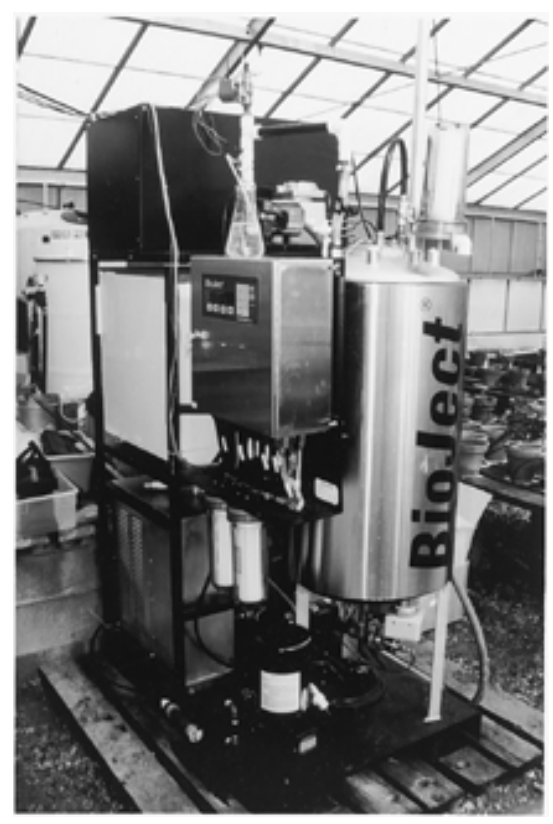

Fig. 1. The EcoSoil Systems BioJect installed in a greenhouse at the University of California, Riverside. 
is capable of producing an effective inoculum source; second, the inoculum density required for effective bacterial colonization of soil; third, how long bacterium should be grown to effectively colonize soil; and, fourth, whether continuous application affects the ability of the bacterium to colonize and persist in the soil. This research was part of a larger study to assess the commercial viability of continuous application technology for biocontrol.

\section{MATERIALS AND METHODS}

Antibiotic resistance marking and stability of $P$. putida 06909-rif/nal. To effectively enumerate biocontrol bacterial populations, $P$. putida 06909-wt was marked with antibiotic resistance. Spontaneous antibiotic resistant mutants of $P$. putida 06909 -wt were isolated by streaking on MGY agar (Mannitol, $10.0 \mathrm{~g}$; Lglutamic acid, $2.0 \mathrm{~g} ; \mathrm{KH}_{2} \mathrm{PO}_{4}, 0.5 \mathrm{~g} ; \mathrm{NaCl}$, $0.2 \mathrm{~g} ; \mathrm{MgSO}_{4}, 0.2 \mathrm{~g}$; Yeast extract, $0.25 \mathrm{~g}$; agar, $18 \mathrm{~g}$; with a final volume of 1 liter in DI $\mathrm{H}_{2} \mathrm{O}$ ) amended with increasing concentrations of rifampicin (Sigma, St. Louis, $\mathrm{MO})$. Concentrations were increased from $1 \mathrm{mg} / \mathrm{liter}, 5 \mathrm{mg} / \mathrm{liter}, 10 \mathrm{mg} / \mathrm{liter}, 20$ $\mathrm{mg} / \mathrm{liter}, 35 \mathrm{mg} / \mathrm{liter}$, and finally to 50 $\mathrm{mg} / \mathrm{liter}$. This same procedure was then repeated with nalidixic acid (ICN, Costa Mesa, CA). All resulting colonies had the same morphology and growth characteristics as the original $P$. putida 06909-wt. Five isolates of $P$. putida 06909 were streaked to single colonies twice on MGY agar supplemented with $50 \mathrm{mg} / \mathrm{liter}$ each of rifampicin and nalidixic acid (MGY rif/nal) to ensure purity and then frozen at $-70^{\circ} \mathrm{C}$ in MGY broth with $40 \%$ glycerol. Each isolate was tested for in vitro colonization and inhibition of $P$. parasitica by the method of Yang et al. (23). Each isolate was then tested for stability of antibiotic resistance by growing in $100 \mathrm{ml}$ of MGY broth without antibiotics. After 24 hours, 1 $\mathrm{ml}$ of each culture was transferred to a second flask of medium. This was repeated for 14 days. At the end of the 14 serial cultures, each isolate was plated onto MGY agar with $50 \mathrm{mg} /$ liter rifampicin and $50 \mathrm{mg} /$ liter nalidixic acid (MGY rif/nal) and MGY agar without antibiotics. Populations of $P$. putida that retained resistance to the antibiotics were compared to total populations and an isolate with a nonsignificant difference was selected. This was repeated a second time. A suitable isolate, $P$. putida 06909-rif/nal, was selected. Several soils were surveyed for natural populations of bacteria capable of growth on MGY rif/nal. None were found in soil from two field sites (Lindcove and Woodlake) or from either the Vista coarse sandy loam or Greenfield sandy loam used in these experiments. To test the specificity of MGY rif/nal for P. putida 06909-rif/nal, forty-seven individual bacterial isolates were recovered from a citrus orchard (Lindcove) on MGY rif/nal. The citrus orchard had received applications of $P$. putida 06909-rif/nal in the irrigation water for one year. The 47 bacterial isolates were tested for identity using BIOLOG GN plates (Biolog, Hayward, CA). All had the same carbon source utilization as $P$. putida. Twelve isolates, recovered from another citrus orchard (Woodlake) on MGY rif/nal after applications of $P$. putida 06909-rif/nal through the irrigation water for one year, were subjected to enterobacterial repetitive intergeneric consensus polymerase chain reaction (ERIC-PCR) (8). This technique gives a fingerprint specific for strains of pseudomonads. Each gave the same banding pattern as $P$. putida 06909-wt and the derived Rif/Nal marked strain, $P$. putida 06909-rif/nal. Tests with BIOLOG and ERIC-PCR suggest that populations recovered were representative of $P$. putida 06909-rif/nal and not other organisms.

Operation of BioJect. The BioJect was controlled in a manner consistent with commercial installations of BioJects. The medium used, MD1/2 (Eco Soil Systems), is a proprietary concentrated formulation of glycerol, glutamic acid, proteose peptone, and phosphate buffer. The BioJect dilutes the growth medium at the initiation of a fermentation cycle with filtered, UVirradiated tap water at a rate of $6 \mathrm{ml}$ of concentrate per liter of water. Fermentations were carried out at $24^{\circ} \mathrm{C}$, with aeration for the entire cycle. All fermentations were for 12 hours unless otherwise noted. Inoculum was prepared by streaking from a frozen stock culture onto MGY Rif/Nal. After 3 days cells were scraped from the plate and suspended in $5 \mathrm{ml}$ of sterile distilled water. This was then added to one liter of Tryptic Soy Broth (Difco) and shaken at $250 \mathrm{rpm}$ on a rotary shaker at $24^{\circ} \mathrm{C}$ for $24 \mathrm{~h}$. This stationary phase inoculum, with an average population of $1 \times$ $10^{9} \mathrm{CFU} / \mathrm{ml}$, was then placed in sterile inoculum bags provided by Eco Soil Systems, and placed in the refrigerated compartment of the BioJect at $4^{\circ} \mathrm{C}$. The BioJect was set to use $300 \mathrm{ml}$ of inoculum per fermentation. All fermentations were 75 liters unless otherwise noted. The inoculum remained viable for 4 weeks, but was changed at the end of 3 weeks to maintain consistency. A sanitation cycle was automatically run after each fermentation cycle as designed by the manufacturer. The sanitation cycle rinses the fermentation vessel and lines with UV irradiated water, then with a concentrated solution of peracetic acid, and again with UV irradiated water. In addition, 1/10 strength peracetic acid was used as a rinse for both the media and inoculum lines as recommended by Eco Soil Systems. This reduced the capacity of the BioJect to only two possible medium sources and two possible inoculum sources per machine.

Contamination of BioJect. To assess levels of contamination in the BioJect, $P$. putida 06909-rif/nal was grown in either the BioJect or as simultaneous cultures in shake flasks. Shake flasks consisted of 250 $\mathrm{ml}$ of autoclaved tap water with $6 \mathrm{ml} / \mathrm{liter}$ of $\mathrm{MD} 1 / 2$. When inoculum was prepared for the BioJect, a subsample was withheld and used as inoculum for the shake flasks. Fermentations were 120 liters, resulting in an inoculation rate of $2.5 \mathrm{ml}$ of inoculum per liter of medium. Shake flasks were inoculated at the same time as the BioJect and at the same rate and grown at $24^{\circ} \mathrm{C}$ at $250 \mathrm{rpm}$ on a rotary shaker bench. After 12 $\mathrm{h}$ of growth, antibiotic resistant and total bacterial populations were measured by dilution plating onto MGY rif/nal and Tryptic Soy Agar (TSA) (Difco) that was not supplemented with antibiotics. Preliminary experiments reveled that it was extremely unlikely that contaminants would be resistant to both rifampicin and nalidixic acid. This was repeated for five consecutive BioJect batches of $P$. putida 06909-rif/nal produced over a 26-dayperiod with a single batch of inoculum in the BioJect.

Growth curve in BioJect. A 75-liter fermentation was run for $19 \mathrm{~h}$ as described above. Optical density at $600 \mathrm{~nm}$ was measured nine times starting $8 \mathrm{~h}$ after inoculation and continuing until $19 \mathrm{~h}$ after inoculation.

Irrigation system. An automated dilution and irrigation system was developed to assist in delivery of the biocontrol agent to greenhouse pots. The system consists of a 250-liter tank, a water pump, 4 drip irrigation systems, solenoid valves, float switches, and a computer-based controller. A solenoid valve was installed on the BioJect to deliver bacteria to the dilution tank. The 250-liter dilution tank is capable of $1: 10,1: 5$, and $1: 2$ dilutions with water. Material in the tank is automatically mixed to ensure uniformity in each dilution. Deionized water was used for all experiments because preliminary tests showed population declines in high dilutions $(1: 100,000)$ when using chlorinated tap water. A pump located below the dilution tank provided pressure for the irrigation lines during applications and mixing by recirculating the solution back into the top of the dilution tank. The drip irrigation systems consisted of four independent lines, three of which were connected to the pump to deliver bacteria and the fourth connected to a distilled water source. All lines were pressure-regulated to ensure equal distribution across the entire system. The drip irrigation lines were automatically flushed before each irrigation by opening solenoid valves at the end of each line, ensuring reliable populations of bacteria in the irrigation water. Lines were arranged to allow randomized complete block designs with three bacterial treatments and one water treatment on each of five greenhouse benches. Benches were also isolated through the use of solenoid valves, allowing a separate experiment on 
each bench without cross-contamination. The controller consisted of two $6 \mathrm{~B}$ series digital I/O boards (National Instruments, Austin, TX) connected to a i486 computer via the RS-232 serial protocol. Software to control the equipment was written with LabView version 5.0 (National Instruments) (Fig. 2). This equipment provided a reliable way of delivering frequent, repeatable applications of bacteria.

Soil. Soil used for all greenhouse trials was a Vista coarse sandy loam taken from a citrus grove in Fallbrook, CA, with the following characteristics: $\mathrm{pH} 8.0$; electrical conductivity, $1.30 \mathrm{mmho} / \mathrm{cm}$; organic matter, $0.36 \%$; cation exchange capacity, $14.1 \mathrm{meq} / 100 \mathrm{~g}$; Ca, $4.2 \mathrm{meq} / \mathrm{liter} ; \mathrm{Mg}, 3.6$ meq/liter; Na, 4.6 meq/liter; $\mathrm{Cl}, 3.9$ meq/liter; B, 0.3 ppm; soluble Zn, 16 ppm; soluble Mn, 16 ppm; soluble Fe, 32 ppm; $\mathrm{Cu}, 1.1 \mathrm{ppm}$; N-Total, $0.045 \%$; and soluble $\mathrm{K}, 4.36 \mathrm{ppm}$. Soil used for the seedling bed experiment was a Greenfield sandy loam taken from a grove in Highland, CA, with the following characteristics: $\mathrm{pH} 7.8$; electrical conductivity, $0.73 \mathrm{mmho} / \mathrm{cm}$; organic matter, $0.82 \%$; cation exchange capacity, $7.8 \mathrm{meq} / 100 \mathrm{~g}$; Ca, $3.8 \mathrm{meq} / \mathrm{liter}$ $\mathrm{Mg}, 1.0$ meq/liter; Na, 2.1 meq/liter; $\mathrm{Cl}, \quad 0.8$ meq/liter; B, 0.6 ppm; soluble Zn, 29 ppm; soluble Mn, 28 ppm; soluble Fe, 55 ppm; $\mathrm{Cu}, 3.6 \mathrm{ppm}$; N-Total, $0.072 \%$; and soluble $\mathrm{K}, 7.54 \mathrm{ppm}$. Soils were passed through a $1-\mathrm{cm}$ screen before use. Soils were taken from locations with a history of Phytophthora root rot and are conducive to the development of the disease.

Plant material. Troyer citrange seedlings were used for all experiments. Seedlings were grown in flats for 6 months in UC soil mix 5 (sand and peat mixed 1:1 by volume) and then washed free of planting mix before being transplanted into the soil used for the experiment.

Effect of inoculum density on bulk soil populations of $P$. putida 06909 -rif/nal in the greenhouse. This experiment assessed the impact of inoculum density on the ability of $P$. putida 06909-rif/nal to colonize soil. Treatments consisted of a single application of $P$. putida 06909rif/nal at the start of the experiment or one of three dilutions of inoculum applied with every irrigation. Using the automated dilution system described above, 1:10 dilutions of the inoculum were made and dilutions of 1:10, 1:1000, and 1:100,000 were used as treatments. Inoculum was produced by the fermentor as described above. The single-application treatment received the first application used for the 1:10 dilution treatment and distilled water for each irrigation thereafter. Each pot received $300 \mathrm{ml}$ of the appropriate dilution at every irrigation. Each treatment consisted of 5 replicate clay pots with $250 \mathrm{~g}$ dry wt. of the Vista course sandy loam soil per pot. A single 6-month-old troyer citrus seedling was planted in each pot. Pots were watered every 3 to 5 days as needed. Populations of
P. putida 06909-rif/nal from the BioJect were measured 23 times over the course of the experiment. Soil populations of $P . p u$ tida 06909-rif/nal were measured at 6, 12, and 18 weeks by dilution plating onto MGY rif/nal agar and are expressed on a dry soil weight basis. Soil from which $P$. putida 06909-rif/nal was enumerated was collected from two $1.5 \times 5 \mathrm{~cm}$ cores per pot. The experiment was repeated twice, except the second experiment used 10 replicate pots per treatment. Results were similar between experiments.

Effect of fermentation time on soil populations of $P$. putida 06909 -rif/nal in the greenhouse. The purpose of this experiment was to test the effect of fermentation time on colonization and survival of $P$. putida 06909-rif/nal in soil. Treatments consisted of: first, a single application of $P$. putida 06909-rif/nal taken at $12 \mathrm{~h}$ into a fermentation cycle applied at the initiation of the experiment; second, a single application of $P$. putida 06909-rif/nal taken at $19 \mathrm{~h}$ into a fermentation cycle applied at the initiation of the experiment; third, applications of $P$. putida 06909-rif/nal taken $12 \mathrm{~h}$ into a fermentation cycle applied with every irrigation; and, fourth, applications of $P$. putida 06909 -rif/nal taken $19 \mathrm{~h}$ into a fermentation cycle applied with every irrigation. Applications consisted of $300 \mathrm{ml}$ per pot of a 1:10 dilution of bacterial inoculum grown with the fermentor as described above except fermentations were for $19 \mathrm{~h}$. Single application treatments received the same applications used for the corresponding continuous application treatment on the first irrigation and dis- tilled water for every irrigation thereafter. Each treatment consisted of five replicate clay pots with $250 \mathrm{~g}$ of the Vista course sandy loam soil per pot. A single 6-monthold troyer citrus seedling was planted in each pot. Pots were watered every 3 to 5 days as needed. Populations of $P$. putida 06909-rif/nal from the fermentor were measured 14 times over the course of the experiment. Soil populations of $P$. putida 06909-rif/nal were measured at 6,12 , and 18 weeks by dilution plating onto MGY rif/nal agar and expressed on a dry soil weight basis. Soil used to enumerate $P$. putida 06909-rif/nal was collected from two $1.5 \times 5 \mathrm{~cm}$ cores per pot. The experiment was repeated twice, except the second experiment used 10 replicate pots per treatment. Results were similar between experiments.

Effect of application interval on survival of introduced $P$. putida 06909rif/nal. This experiment tested whether continuous application affected the ability of $P$. putida 06909-rif/nal to colonize and survive in soil better than a single application. This experiment utilized two $1.2 \times 4.9$ $\mathrm{m}$ seedling beds filled with Greenfield sandy loam soil. The beds mimic field conditions except that light was reduced by $30 \%$, as measured by a light meter. Each bed consisted of separate repeat and was divided into seven replicate blocks with one troyer seedling per treatment per block. Treatments consisted of equal populations of $P$. putida 06909 -rif/nal delivered as either 10 applications every 2 to 3 days or as a single application, at $10 \times$ the concentration, applied at the end of the

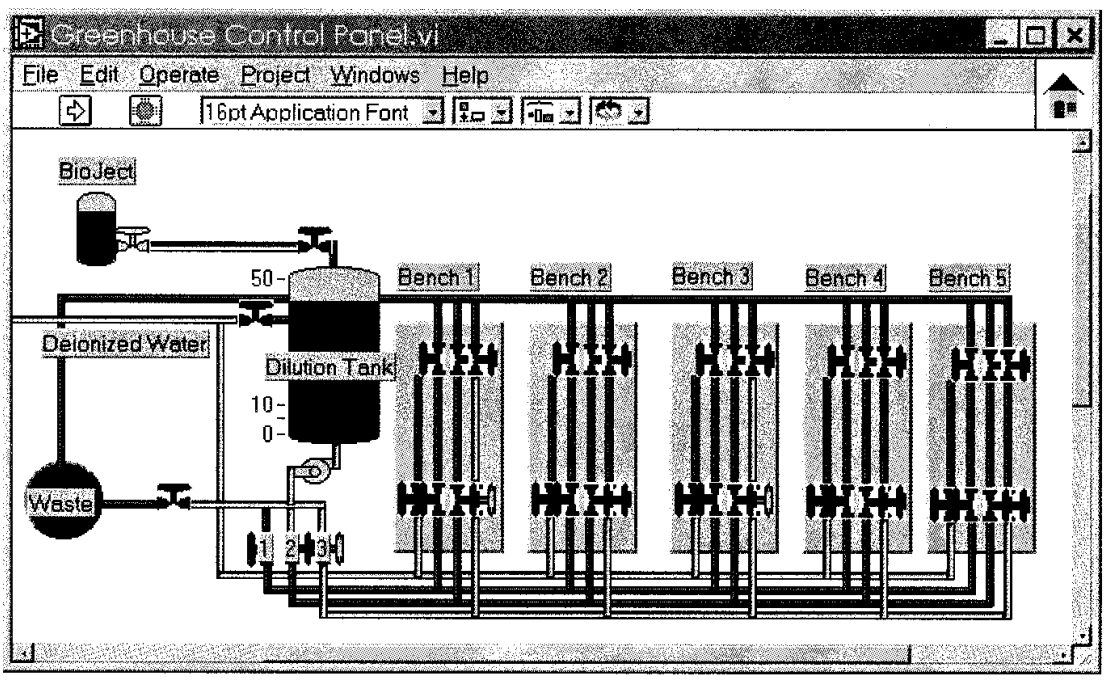

Fig. 2. Control panel from LabVIEW software showing layout of greenhouse. A bacterial culture grown in the BioJect is injected into the dilution tank and diluted with deionized water. The dilution is then mixed and then pumped through one of three lines to the benches. Here benches one and three are being watered through line three. Solenoid valves at the end of the irrigation lines are opened at the beginning of each irrigation to flush old material out of the lines. After irrigation through the first line is complete, a portion of the dilution can be reserved for further dilutions through the other irrigation lines. Deionized water with no bacteria can be applied through the fourth line. Once all irrigations are complete, the dilution tank and all of the lines are flushed with deionized water. This design was adapted to deliver bacteria from 12- and 19-h fermentations through two lines and could be adapted to deliver different organisms from different fermentations of the BioJect. 
continuous application treatments. Bacteria were applied over 26 days in the continuous application treatment, while water was applied to the single application treatment until the single, $10 \times$ application was made at the time of the final continuous application treatment. The experiment was continued for an additional 26 days, during which water alone was applied to all trees. Soil populations of $P$. putida 06909-rif/nal were assessed 56 days after the initiation of the experiment by dilution plating onto MGY rif/nal from rhizosphere soil adhering to the roots of each seedling. Populations are based on a dry soil weight.

Statistical analysis. Bacterial data was transformed with the $\log (Y+1)$ transformation before statistical analysis. Homogeneity of variance was tested with Brown and Forsythe's test for equality of variance and where variance was significantly different, Welche's analysis of variance (ANOVA) was used. Otherwise, GLM (SAS Institute, Cary, NC) was used for analysis of variance and means were separated with Fisher's least significant difference for pairwise comparisons and WallerDuncan $k$-ratio $t$ test for multiple comparisons. Where appropriate, single degree of freedom orthogonal contrasts were used. Regressions and t-tests were done in $\mathrm{Mi}$ crosoft Excel.

\section{RESULTS}

Contamination of BioJect. There were no significant differences in populations of bacteria in cultures of $P$. putida 06909rif/nal when grown on MGY rif/nal and total bacterial populations grown on TSA in either the BioJect or shake flask cultures, indicating contamination was below detection. Mean populations ranged from $8.38 \log \mathrm{CFU} / \mathrm{ml}$ on $\mathrm{MGY}$ rif/nal from shake flasks to $8.82 \log \mathrm{CFU} / \mathrm{ml}$ on TSA for the Bioject.

Growth curve in BioJect. The growth curve in the BioJect showed a linear increase in optical density throughout the 19$\mathrm{h}$ fermentation with $r^{2}=0.9642$ (Fig. 3). This indicates that $P$. putida 06909 -rif/nal was undergoing logarithmic growth for this

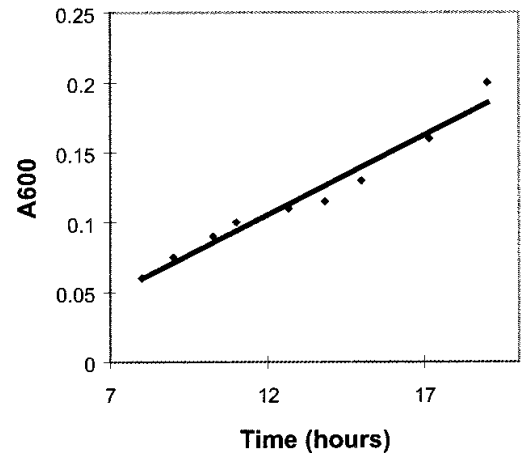

Fig. 3. Growth curve for Pseudomonas putida 06909 rif/nal in the BioJect. period and did not reach the stationary growth phase.

Effect of inoculum density on bulk soil populations of $P$. putida $06909 \mathrm{rif} / \mathrm{nal}$ in the greenhouse. Initial inoculum densities from cultures produced by the BioJect ranged from $2.0 \times 10^{7}$ to $1.9 \times 10^{9} \mathrm{CFU} / \mathrm{ml}$ with a mean of $4.5 \times 10^{8} \mathrm{CFU} / \mathrm{ml}$ before dilutions. The single application was $6.7 \times$ $10^{6} \mathrm{CFU} / \mathrm{ml}$. All soil populations showed significant declines between the sampling periods except for the highest $(1: 100,000)$ dilution rate (Fig. 4). At 18 weeks, continuous application of a 1:10 dilution resulted in significantly higher populations of $5.97 \mathrm{log}$ CFU/g soil of $P$. putida 06909rif/nal in the soil than any other treatment. Populations of $P$. putida 06909-rif/nal in soil receiving the continuous application with a 1:1,000 dilution treatment were closest to those arising from the single application treatment; populations in these treatments never differed significantly. Continuous application of a 1:100,000 dilution resulted in significantly lower populations at 6 and 12 weeks, but by 18 weeks populations were not significantly different from those in any of the other treatments except for the continuous application of a 1:10 dilution treatment.

Effect of fermentation length on soil populations of $\boldsymbol{P}$. putida. Average populations of $P$. putida 06909-rif/nal from the BioJect, before the 1:10 dilution, were 5.6 $\times 10^{8} \mathrm{CFU} / \mathrm{ml}$ for both 12 and $19 \mathrm{~h}$, with a maximum of $1.1 \times 10^{9} \mathrm{CFU} / \mathrm{ml}$ at $12 \mathrm{~h}$ and $1.8 \times 10^{9} \mathrm{CFU} / \mathrm{ml}$ at $19 \mathrm{~h}$ and a minimum of $1.7 \times 10^{5} \mathrm{CFU} / \mathrm{ml}$ at $12 \mathrm{~h}$ and $3.0 \times 10^{6}$ $\mathrm{CFU} / \mathrm{ml}$ at $19 \mathrm{~h}$. A t-test showed no significant differences between populations at 12 and $19 \mathrm{~h}$. Single applications were $8.4 \times$ $10^{7} \mathrm{CFU} / \mathrm{ml}$ and $8.6 \times 10^{6} \mathrm{CFU} / \mathrm{ml}$ for the 12- and 19-h treatments, respectively. Populations in all treatments declined significantly over the 18 -week period, except for those in the continuous application of inoculum from 19-h fermentations (Fig. 5). By the end of 18 weeks, continuous application of the 19-h fermentations treatment gave rise to significantly higher soil populations than all other treatments. The continuous application of 12-h fermentations treatment gave rise to significantly higher populations than the single application of a 12-h fermentation, but neither gave rise to populations significantly different from the single application of a 19-h fermentation. Orthogonal contrasts of populations between 19 and 12-h fermentations were significantly different at 12 and 18 weeks but not at 6 weeks.

Effect of application interval on survival of $P$. putida 06909 -rif/nal. When $P$. putida 06909-rif/nal was applied once at $10 \times$ at the end of the experiment and compared to $10,1 \times$ applications at 2- to 3-day intervals, soil populations were significantly different $(P=0.0206)$ between treatments in the second experiment but not in the first experiment (Table 1). In the first experiment, the variance for the single $10 \times$ application was significantly larger than for the $10,1 \times$ applications. Welche's ANOVA showed no treatment differences.

\section{DISCUSSION}

The Bioject produced clean, high density inoculum in $12 \mathrm{~h}$, allowing two inoculum applications a day. Populations in the BioJect never reached stationary phase after $19 \mathrm{~h}$, but this may be due to the complex medium. These results were similar to those achieved in shake flask cultures in the laboratory with the same medium, where the culture did not reach stationary phase until approximately $24 \mathrm{~h}$ (data not shown). The temperature optimum of $P$. putida 06909-rif/nal is approximately $28^{\circ} \mathrm{C}$. By using a higher temperature for fermentations, the growth rate could be

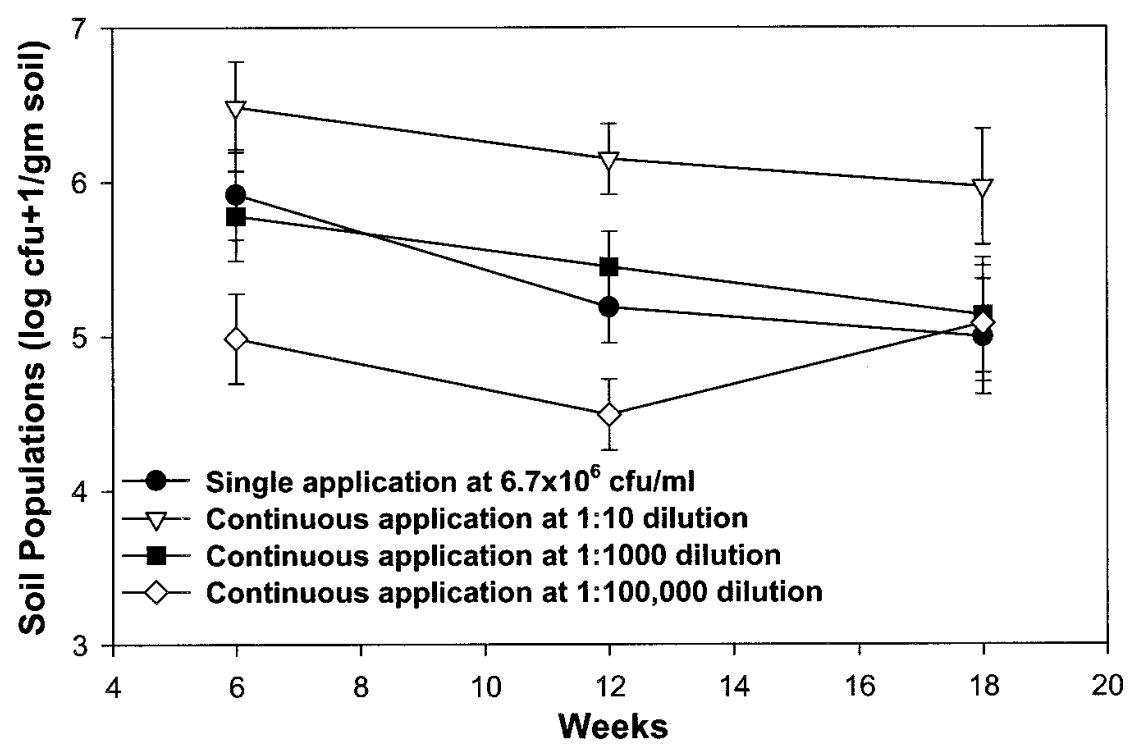

Fig. 4. Effect of inoculum density on soil populations of Pseudomonas putida 06909rif/nal in the greenhouse. Error bars represent the Waller-Duncan $k$-ratio $t$ test. 
increased, resulting in higher inoculum densities. We conducted experiments at $24^{\circ} \mathrm{C}$ since this is near room temperature and close to the average soil temperature in the field and the greenhouse.

Higher inoculation rates resulted in higher soil populations. Nevertheless, increasing inoculum densities implies decreasing volumes of irrigation water that can be treated. A 120-liter fermentation at the highest dilution rate tested $(1: 100,000)$ while the lowest dilution rate (1:10) would only treat 1,200 liters. The increase in soil populations seen with the low dilution rate does not make up for the loss in volume of irrigation water that can be treated. The highest dilution rate resulted in a final soil population similar to either the single application or the 1:1,000 dilution, suggesting that large acreages could be treated at the high dilution rates as effectively as at the lower dilution rates.

There was a trade off between length of fermentation and number of fermentations that could be completed in 1 day. Soil populations resulting from continuous applications of 19-h fermentations yielded an eight-fold increase over all other treatments. These results agree with Vandenhove et al. (22), who found that late would treat $12,000,000$ liters of water,

exponential phase cultures survived better in soil than cultures inoculated at stationary phase or early exponential phase.

Application interval did not have a large impact on populations of P. Putida 06909-rif/nal. The first experiment showed no significant differences between soil populations and the second differed by only $0.67 \log$ CFUs per gram of soil. The 10, $1 \times$ applications were exposed to the soil environment for up to 52 days, whereas the single, $10 \times$ application was exposed to the soil environment for only 26 days. Declines due to soil drying during this extra 26-day-period could account for these differences seen in the second experiment.

Some of these results did not match those from field trials, where bacterial populations increased over time under continuous application treatments $(16,17)$. Preliminary field results showed $P$. putida 06909-rif/nal populations are influenced heavily by the drying of the soil. Many of the severe population declines seen in these experiments were likely artifacts of the extreme wet-dry cycles under greenhouse conditions. In the field the large bulk of the soil provided a buffer against extreme moisture fluctuations that was difficult to duplicate in a greenhouse. The overall

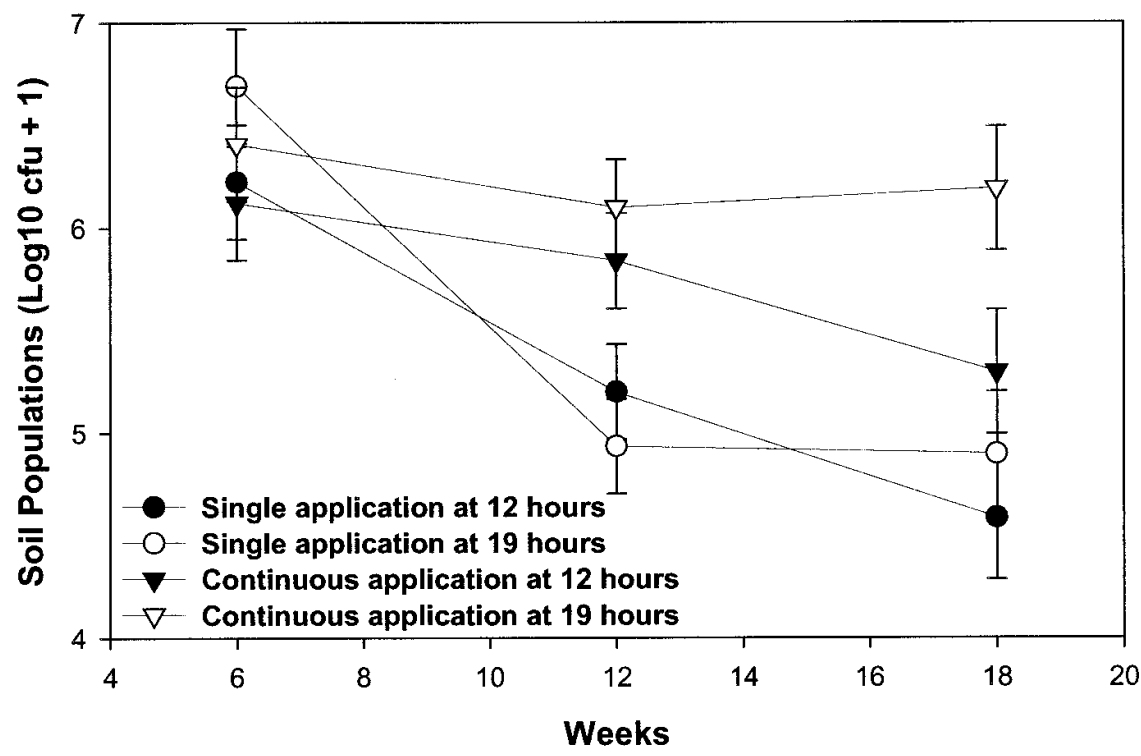

Fig. 5. Soil populations of Pseudomonas putida 06909 rif/nal after 12- or 19-h fermentations and with either single applications or continuous applications. Error bars represent Waller-Duncan $k$-ratio $t$ test.

Table 1. Mean populations of Pseudomonas putida 06909 rif/nal in seedling beds for different inoculum application intervals

\begin{tabular}{lcc}
\hline & \multicolumn{2}{c}{ Soil populations $(\mathbf{L o g}$ CFU+1/gm) } \\
\cline { 2 - 3 } Treatment $^{\mathrm{a}}$ & Experiment 1 & Experiment 2 \\
\hline 10 at $1 \times$ inoculum & $4.17 \mathrm{~A}$ & $4.69 \mathrm{~B}$ \\
1 at $10 \times$ inoculum at end & $4.43 \mathrm{~A}$ & $5.36 \mathrm{~A}$ \\
\hline
\end{tabular}

${ }^{a}$ The 10 applications of $1 \times$ inoculum were applied at 2 - to 3 -day intervals over a 26-day period. The single application of $10 \times$ inoculum was applied at the same time as the final application of the 10 applications of $1 \times$ inoculum. Soil populations were enumerated 26 days later. trends of the results, however, were similar to field results.

These data reveal that the BioJect can treat large volumes of irrigation water with pure cultures of the bacterial inoculant. It can produce up to two 25 -gallon applications per fermentor a day. Repetitive applications of bacterial inoculum established soil populations as effectively as single applications, and the lower inoculum dose per application with more frequent applications would be more cost effective over time. This should make the BioJect suitable for producing inoculum for biocontrol studies for field-scale, commercial trials.

\section{LITERATURE CITED}

1. Bahme, J. B., Schroth, M. N., Van Gundy, S. D., Weinhold, A. R., and Tolentino, D. M. 1988. Effect of inocula delivery systems on rhizobacterial colonization of underground organs of potato. Phytopathology 78:534-542.

2. Becker, J. O., and Schwinn, F. J. 1993. Control of soilborne pathogens with living bacteria and fungi: status and outlook. Pestic. Sci. 37:355-363.

3. Cook, R. J. 1993. Making greater use of introduced microorganisms for biological control of plant pathogens. Annu. Rev. Phytopathol. 31:53-80.

4. Harman, G. E. 2000. Myths and dogmas of biocontrol, changes in perceptions derived from research on Trichoderma harzianum T22. Plant Dis. 84:377-393.

5. Harman, G. E., and Lumsden, R. D. 1990. Biological disease control. Pages 259-280 in The Rhizosphere. J. M. Lynch, ed. John Wiley and Sons, West Sussex, UK.

6. Kim, D.-S., Weller, D. M., and Cook, R. J. 1997. Population dynamics of Bacillus sp. L324-92R-12 and Pseudomonas fluorescens 2-79RN-10 in the rhizosphere of wheat. Phytopathology 87:559-564.

7. Lewis, J. A., and Papavizas, G. C. 1991. Biocontrol of plant diseases: The approach for tomorrow. Crop. Prot. 10:95-104.

8. Louws, F. J., Fulbright, D. W., Stephens, C. T., and De Bruijn, F. J. 1994. Specific genomic fingerprints of phytopathogenic Xanthomonas and Pseudomonas pathovars and strains generated with repetitive sequences and PCR. Appl. Environ. Microbiol. 60:2286-2295.

9. Martensson, A. M. 1990. Competitiveness of inoculant strains of Rhizobium leguminosarum biovar trifolii in red clover using repeated inoculation and increased inoculum levels. Can. J. Microbiol. 36:136-139.

10. Mathre, D. E., Cook, R. J., and Callan, N. W. 1999. From discovery to use: Traversing the world of commercializing biocontrol agents for plant disease control. Plant Dis. 83:972983.

11. Papavizas, G. C., and Lumsden, R. D. 1980. Biological control of soilborne fungal propagules. Annu. Rev. Phytopathol. 18:389-413.

12. Powell, K. A. 1991. Strategies and guidelines for the development of biological control Pages 423-428 in Biotic Interactions and SoilBorne Diseases, A. B. R. Beemster, M. Gerlagh, M. A. Ruissen, B. Schippers, A. Tempel, eds. Elsevier, Amsterdam, Netherlands.

13. Schippers, B., Bakker, A. W., and Bakker, P. A. H. M. 1987. Interactions of deleterious and beneficial rhizosphere microorganisms and the effect of cropping practices. Annu. Rev. Phytopathol. 25:339-358.

14. Schroth, M. N., and Becker, J. O. 1990. Concepts of ecological and physiological activities of rhizobacteria related to biological 
control and plant growth promotion. Pages 389-414 in: Biological Control of Soil-Borne Plant Pathogens, D. Hornby, ed. CAB International, Wallingford, UK.

15. Schroth, M. N., and Weinhold, A. R. 1986. Root-colonizing bacteria and plant health. Hortscience 21:1295-1298.

16. Steddom, K. C., and Menge, J. A. 1998. Continuous application of the biocontrol bacterium, Pseudomonas putida 06909, increases soil populations over a single application. (Abstr.) Phytopathology 88:S85.

17. Steddom, K. C., and Menge, J. A. 1999. Continuous application of the biocontrol bacterium, Pseudomonas putida 06909, im- proves biocontrol of Phytophthora parasitica on citrus. (Abstr.) Phytopathology 89:S75.

18. Troxler, J., Zala, M., Moenne-Loccoz, Y., Keel, C., and Defago, G. 1997. Predominance of nonculturable cells of the biocontrol strain Pseudomonas fluorescens $\mathrm{CHA} 0$ in the surface horizon of large outdoor lysimeters. Appl. Environ. Microbiol. 63:3776-3782.

19. Turney, J. 1995. The biological control of Phytophthora root rot of citrus using rhizobacteria. Ph.D. diss. Univ. Calif., Riverside.

20. Turney, J. K., and Menge, J. A. 1993. Biocontrol of Phytophthora citrophthora root rot of citrus. (Abstr.) Phytopathology 83:1348.

21. Turney, J. K., Yang, C. H., Cooksey, D. A., and Menge, J. A. 1994. Mechanisms of biocontrol of Phytophthora citrophthora root rot of citrus by Pseudomonas putida. (Abstr.) Phytopathology 84:1091.

22. Vandenhove, H., Merckx, R., Wilmots, H. and Vlassak, K. 1991. Survival of Pseudomonas fluorescens inocula of different physiological stages in soil. Soil Biol. Biochem. 23:1133-1142.

23. Yang, C. H., Menge, J. A., and Cooksey, D. A. 1994. Mutations affecting hyphal colonization and pyoverdine production in pseudomonads antagonistic toward Phytophthora parasitica. Appl. Environ. Microbiol. 60:473481. 